\title{
Role of 5-ASA in IBD therapy
}

5 -AMINOSALICYLIC ACID (5-ASA) IS THE ACTIVE PRINCIPAL OF THE drug sulphasalazine (SAS). 5-ASA is available in carrier-mediated forms; the prodrug is delivered to the large intestine, where bacterial reaction breaks an azo-bond and releases the active principal. For $\mathrm{SAS}$, the release is of the active principal, 5-ASA, and inactive sulphapyridine. For olsalazine (Dipentum, Pharmacia), splitting the azo-bond releases two molecules of 5-ASA. Other prodrugs, balsalazide and ipsalazide, are not available in Canada. Enteric-coated, slowrelease, $\mathrm{pH}$-dependent forms of 5-ASA are available in North America: Asacol (Procter \& Gamble), Salofalk (Axcan Canada), Rowasa (Solvay, Georgia). These preparations avoid excessive upper intestinal absorption, and theoretical renal damage. Salofalk and Rowasa are released in the distal ileum, Asacol in the right colon. Another preparation, Pentasa (Nordic), is a formulation of 5-ASA granules covered with ethyl cellulose, which allows slow release starting in the proximal small bowel.

5-ASA acts on soluble mediator production. It is a weak 5-lipoxygenase inhibitor and it modulates leukocyte function. It inhibits prostaglandins, thromboxanes, platelet-activating factor, tumour necrosis factor, interleukin-1, intestinal mast cell and basophil stimulated histamine release. It is an effective scavenger of oxygen free radicals. The relative importance of these actions is not known.

The prodrug SAS is associated with an approximately $30 \%$ incidence of side effects, predominantly related to the sulphapyridine component. Desensitization is helpful for some, but not for hypersensitivity reactions such as agranulocytosis, hemolysis or aplastic anemia. Other rare side effects include male infertility and folate deficiency. Side effects associated with 5-ASA tend to be dose-related and infrequent - headache, nausea, epigastric distress and diarrhea are common. Rare complications of 5-ASA include acute pancreatitis, pericarditis, thrombocytopenial and renal tubular damage.

5-ASA is effective in treating inflammatory bowel disease (IBD). Its exact efficacy is difficult to ascertain, despite careful literature review, due to: lack of accurate definitions of remission versus improvement; failure to define the exact type or extent of IBD; differing results depending on whether placebo or active drugs are used for controls; different end-points; different scoring systems; varying doses; different treatment periods; and the absence of power calculations for accurate estimates of number of patients required. Placebo responses in acute ulcerative colitis (UC) range from 5 to $38 \%$, and active drug dose responses from 24 to $63 \%$, using doses up to $4.8 \mathrm{~g}$ over three to eight weeks. Using the same dose for different time periods shows a tendency for increased efficacy in clinical response, but not in endoscopic response. In maintenance therapy for UC, comparisons of SAS versus placebo over six to 12 months reveal a therapeutic gain of 43 to $50 \%$, with a therapeutic gain of $24 \%$ using increasing doses of SAS. There are many studies showing equal efficacy in maintaining remission between SAS and another prodrug, Dipentum, as well as between SAS and enteric-coated 5-ASA. Meta-analyses have shown that 5-ASA is equivalent to SAS in mild to moderate acute UC and in maintenance therapy. Similarly, the use of topical 5-ASA in UC is very effective for enemas, 85 to $90 \%$ using $4 \mathrm{~g}$ at night-time for four to 12 weeks, and for suppositories, similar efficacy using either $500 \mathrm{mg}$ bid or tid for six weeks. For maintenance

Gastroenterology in the 90 s is a series of short articles addressing topical, controversial issues in the treatment of gastrointestinal disorders. The series is made possible through an educational grant from Astra Pharma Inc therapy, $1 \mathrm{~g}$ at night-time for enemas, and $0.5 \mathrm{~g}$ every second night for suppositories, are effective treatments. Recent meta-analysis of topical 5-ASA in UC confirms significant benefits over placebo for both active disease and maintenance therapy.

5-ASA is effective in active Crohn's disease (CD). There is a $32 \%$ therapeutic gain with SAS $3 \mathrm{~g} /$ day compared with placebo over a four-mouth period. This was later confirmed in the National Cooperative Crohn's Disease Study where a subgroup with colitis responded better. In a recent study, a $24 \%$ therapeutic gain of Pentasa over placebo was seen in 310 patients randomized to various doses over 16 weeks. There was no difference between placebo, 1 or $2 \mathrm{~g}$ in this study. In maintenance therapy, Pentasa is beneficial, compared with placebo, in a subgroup of patients who had relapsed within three months before enrolment. Other, smaller studies have shown no effect when either Pentasa or SAS was compared with placebo. However, in a large group of patients treated with SAS followed for up to two years, there was a therapeutic gain of $25 \%$, and in another study of 12 months' duration, patients randomized to Mesasal (SmithKline Beecham) experienced a 24\% therapeutic gain over those randomized to placebo. Patients with $\mathrm{CD}$ on placebo had remission rates varying from 35 to $54 \%$, compared with $60 \%$ on SAS and $78 \%$ on Mesasal over 12 months. These findings were confirmed in a recent meta-analysis where maintenance therapy with 5-ASA or SAS reduced the likelihood of clinical relapse at one year.

5-ASA is a well tolerated medication with few side effects, allowing increases in effective dose. It is recommended that 5 -ASA $4 \mathrm{~g}$ be given orally for active IBD, with increases as necessary. It is uncertain whether continuous active treatment should be advised for maintenance therapy, ie, $4 \mathrm{~g} /$ day or the standard dose of $2 \mathrm{~g} /$ day. Different preparations can be used to target the site of disease, and when given orally, appear to be as effective as SAS in maintaining remission. However, SAS is much less expensive, and when tolerated, is effective therapy. 5-ASA given to SAS-intolerant patients is of therapeutic benefit in most, with the caveat of occasional allergic reaction to 5-ASA.

\section{FURTHER READING}

Anthonisen P, et al. Scand J Gastroenterol 1974;9:549-54.

Azad Khan AK, et al. Gut 1980;21:232-40.

Azad Khan AK, et al. Lancet 1977;ii:891-5.

Daneshmend TK. Lancet 1991;337:1297-8.

Deprez P, et al. Lancet 1989;ii:445-6.

Dissanayake AS, Truelove SC. Gut 1973;14:923-6.

Donald JP, Wilkinson SP. Postgrad Med J 1985;61:1047-8.

Jenss H, et al. Am J Gastroenterol 1990;85:332-4.

Lauritsen K, et al. In: Shaffer EA, ed. Medical Management of IBD.

Montreal: Medicopea International Inc, 1992. (Proc)

Malchow H, et al. Gastroenterology 1984;86:249-66.

Meyers S, et al. Gastroenterology 1987;93:1255-62.

Misiewicz JJ, et al. Lancet 1965;i:185-8.

Rachmilewitz D. Br Med J 1989;298:82-6.

Rutgeerts P. Aliment Pharmacol Ther 1989;3:183-91.

Schroeder KW, et al. N Engl J Med 1987;317:1625-9.

Singleton JW, et al. Gastroenterology 1993;104:1293-301.

Summers RW, et al. Gastroenterology 1979;77:829-42.

Sutherland LR, et al. Ann Intern Med 1993;118:540-9.

Thomson ABR. Aliment Pharmacol Ther 1990;4:55-64.

van Hees PAM, et al. Gut 1980;21:632-5.

Williams CN. Can J Gastroenterol 1990;4:472-5.

CN Williams, MD, FRCPC Halifax, Nova Scotia 


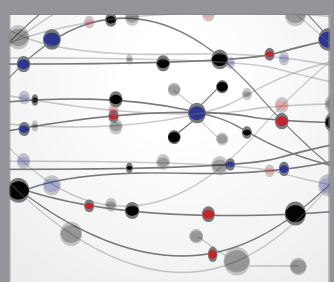

The Scientific World Journal
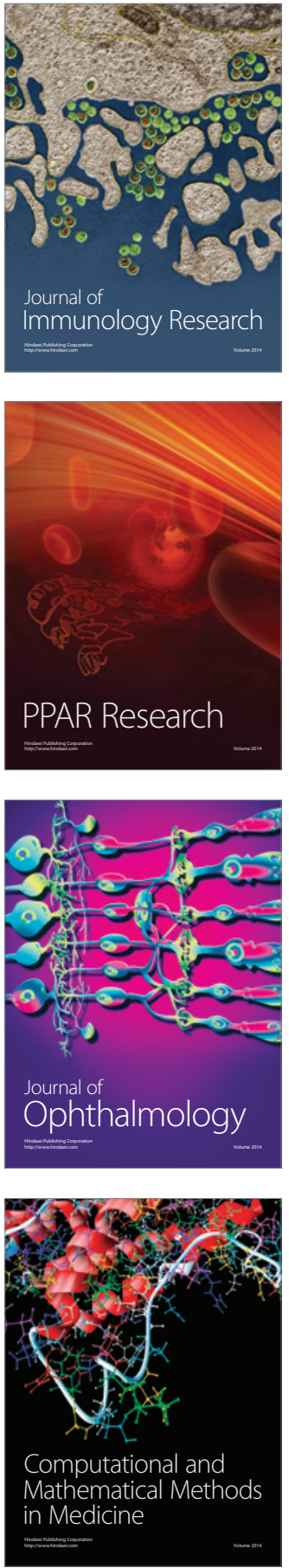

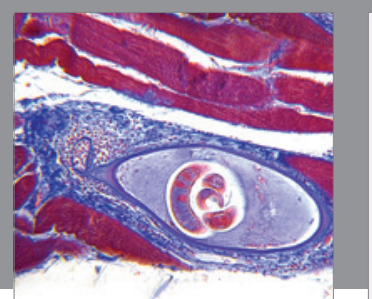

Gastroenterology Research and Practice

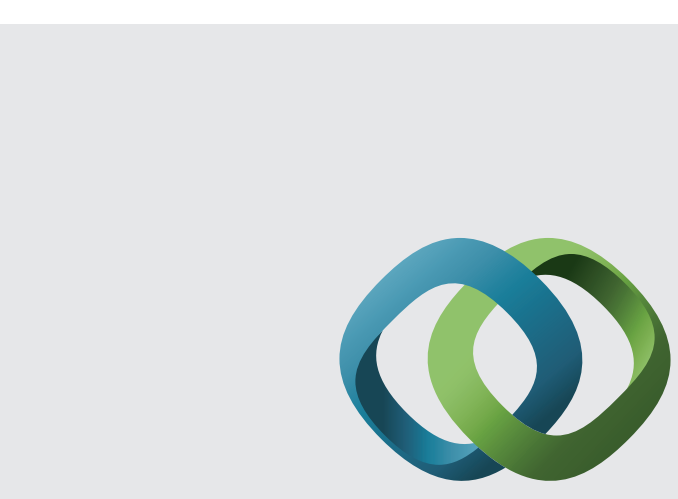

\section{Hindawi}

Submit your manuscripts at

http://www.hindawi.com
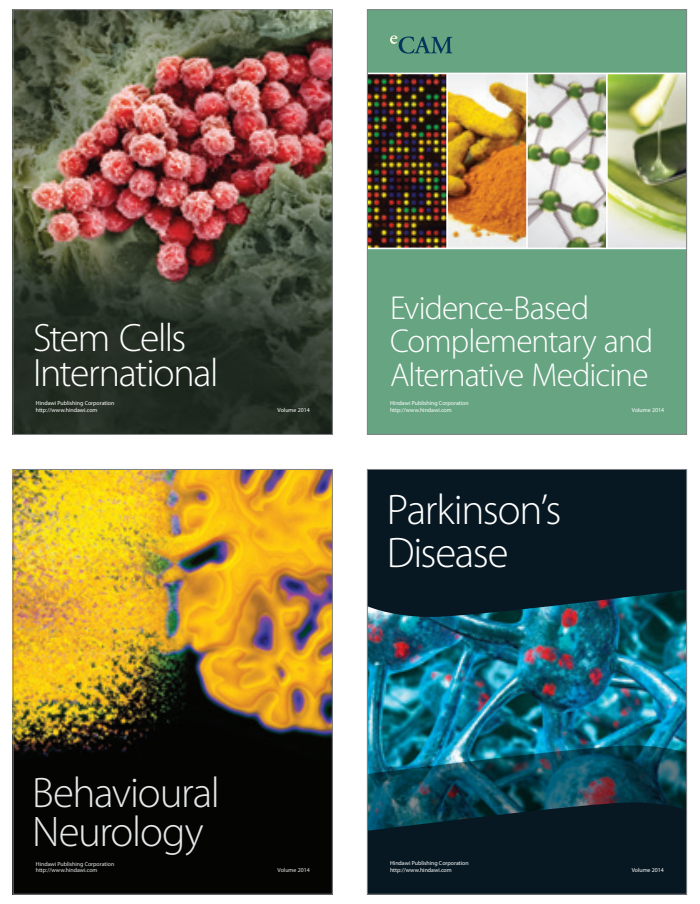
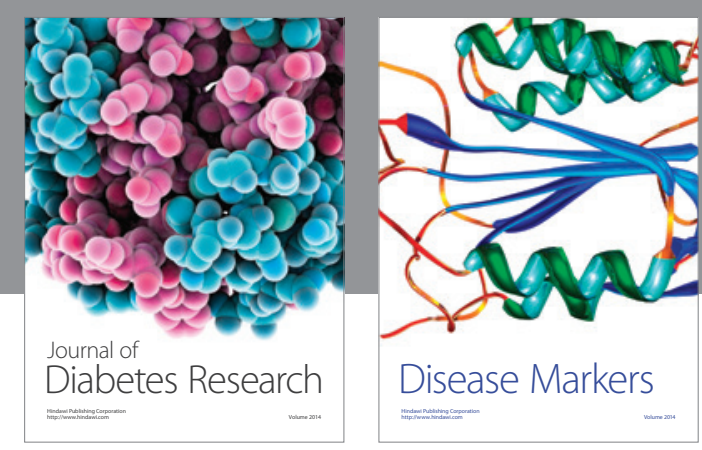

Disease Markers
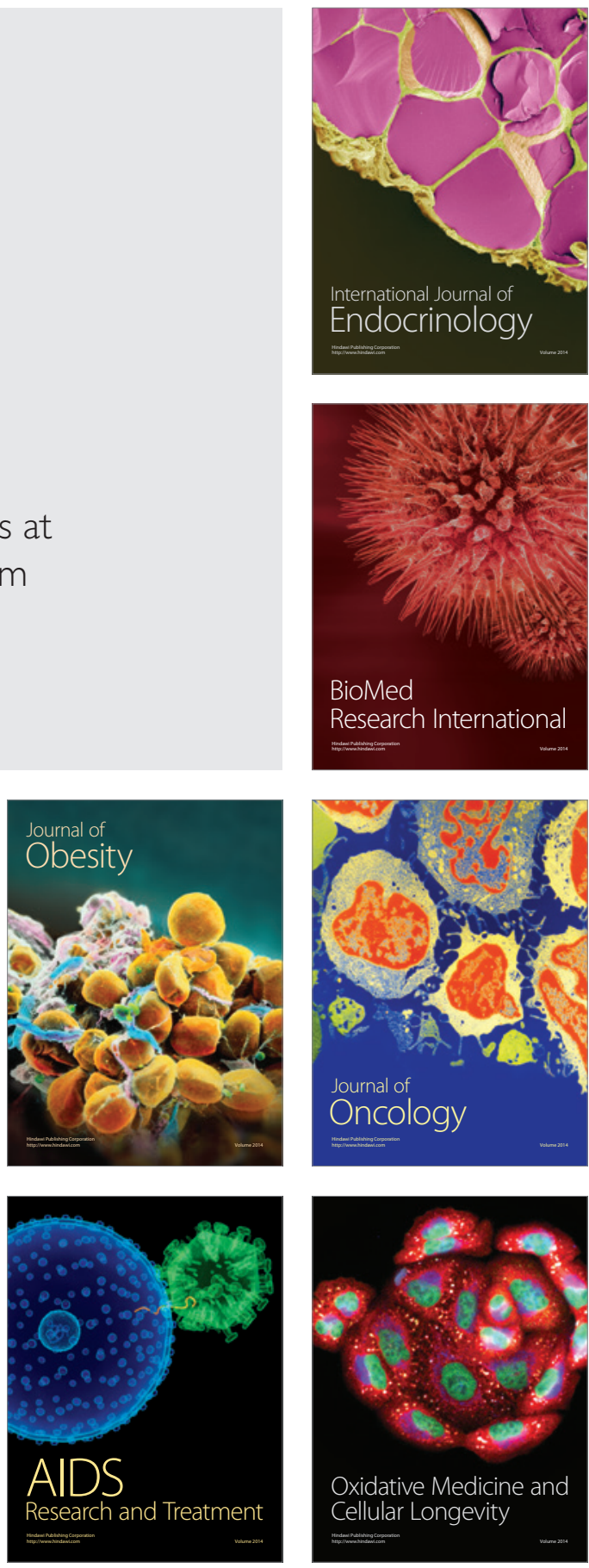